\title{
Design, realization and test of C-band accelerating structures for the SPARC_LAB linac energy upgrade
}

\author{
D. Alesini ${ }^{\text {a }}$, M. Bellaveglia ${ }^{a}$, M.E. Biagini ${ }^{a}$, R. Boni ${ }^{a}$, M. Brönnimann ${ }^{\text {b }}$, F. Cardelli ${ }^{\text {c,d }}$, \\ P. Chimenti ${ }^{a}$, R. Clementi ${ }^{a}$, G. Di Pirro ${ }^{a}$, R. Di Raddo ${ }^{a}$, M. Ferrario ${ }^{a}$, L. Ficcadenti ${ }^{\text {c,d }}$, \\ A. Gallo ${ }^{a}$, R. Kalt ${ }^{b}$, V. Lollo ${ }^{a}$, L. Palumbo ${ }^{c, d}$, L. Piersanti ${ }^{\text {c,d,*, T. Schilcher }}{ }^{\text {b }}$ \\ a INFN Laboratori Nazionali di Frascati, Via Enrico Fermi 40, 00044, Frascati, Italy \\ ${ }^{\mathrm{b}}$ Paul Scherrer Institut, 5232 Villigen, Switzerland \\ c INFN Sezione di Roma, P.le Aldo Moro 2, 00185, Roma, Italy \\ 'Università di Roma "La Sapienza", P.le Aldo Moro 2, 00185, Roma, Italy
}

\section{A R T I C L E I N F O}

\section{Article history:}

Received 9 May 2016

Received in revised form

2 September 2016

Accepted 5 September 2016

Available online 6 September 2016

Keywords:

C-band

High gradient

Constant impedance

Tuning

Breakdown rate

Rf breakdown

\begin{abstract}
A B S T R A C T
The energy upgrade of the SPARC_LAB photo-injector at LNF-INFN (Frascati, Italy) has been originally conceived replacing one low gradient $(13 \mathrm{MV} / \mathrm{m}$ ) $3 \mathrm{~m}$ long SLAC type S-band traveling wave (TW) section with two $1.4 \mathrm{~m}$ long C-band accelerating sections. Due to the higher gradients reached by such structures, a higher energy beam can be obtained within the same accelerator footprint length. The use of C-band structures for electron acceleration has been adopted in a few FEL linacs in the world, among others, the Japanese Free Electron Laser at SPring-8 and the SwissFEL at Paul Scherrer Institute (PSI). The C-band sections are traveling wave, constant impedance structures with symmetric input and output axial couplers. Their design has been optimized for the operation with a SLED RF pulse compressor. In this paper we briefly review their design criteria and we focus on the construction, tuning, low and high-power RF tests. We also illustrate the design and realization of the dedicated low level RF system that has been done in collaboration with PSI in the framework of the EU TIARA project. Preliminary experimental results appear to confirm the operation of such structures with accelerating gradients larger than $35 \mathrm{MV} / \mathrm{m}$.
\end{abstract}

(c) 2016 Elsevier B.V. All rights reserved.

\section{Introduction}

SPARC_LAB [1] (Sources for Plasma Accelerators and Radiation Compton with Lasers and Beams) is a $160 \mathrm{MeV}$ linac based test facility in operation since 2006 at the INFN Frascati laboratories (LNF-INFN) [2]. The linac comprises a 1.6-cell standing-wave UCLA/BNL/SLAC RF gun [3] and three constant-gradient S-Band $(2.856 \mathrm{GHz}) 2 \pi / 3 \mathrm{TW}$ structures. It provides high brightness electron beams $\left(\approx 10^{15} \mathrm{~A} / \mathrm{m}^{2} \mathrm{rad}^{2}\right.$ ), together with high power laser pulses (300 TW) from the FLAME facility [4], to four experimental beamlines for a wide spectrum of research activities based on novel radiation sources, such as: SASE-FEL in visible light [5], velocity bunching [6], seeding [7], X-ray production by inverse Thomson scattering [8] and high power $\mathrm{THz}$ radiation both broadband and narrowband [9,10]. A sketch of the machine layout has been reported in Fig. 1. The energy upgrade of the photo-injector, from $160 \mathrm{MeV}$ to more than $240 \mathrm{MeV}$, has been originally

\footnotetext{
* Corresponding author at: INFN Sezione di Roma, P.le Aldo Moro 2, 00185, Roma, Italy.

E-mail address: luca.piersanti@lnf.infn.it (L. Piersanti).
}

proposed adopting C-band $(5.712 \mathrm{GHz})$ structures to exploit the larger accelerating gradients available with a higher working frequency. Moreover, according to beam dynamics simulations, very promising results in terms of achievable beam quality [11] could be obtained combining a S-band injector and a C-band booster. The use of C-band structures for electron acceleration and production of high quality beams has been proposed and adopted in different linac facilities worldwide [12-17]. Such a choice has also been planned, and successfully tested, for the injector linac of the electron-positron collider SuperKEKB $[18,19]$. At present, the two main FEL projects that make use of this technology are the Japanese FEL SPring-8 [12,13], and the SwissFEL at PSI [16]. In the former, TW damped structures have been chosen for multi-bunch operation [20-24]. The damping of the high order modes (HOM) is realized with the choke mode technique [15]. The structures, operating with a $3 \pi / 4$ phase advance per cell, have been successfully tested reaching accelerating gradients of $37 \mathrm{MV} / \mathrm{m}[25,26]$. The latter project, instead, foresees to operate the accelerating sections with an average gradient of $26 \mathrm{MV} / \mathrm{m}$, even though preliminary tests made either on prototypes with reduced number of cells [27], or with full length structures [28] reached gradients larger than 


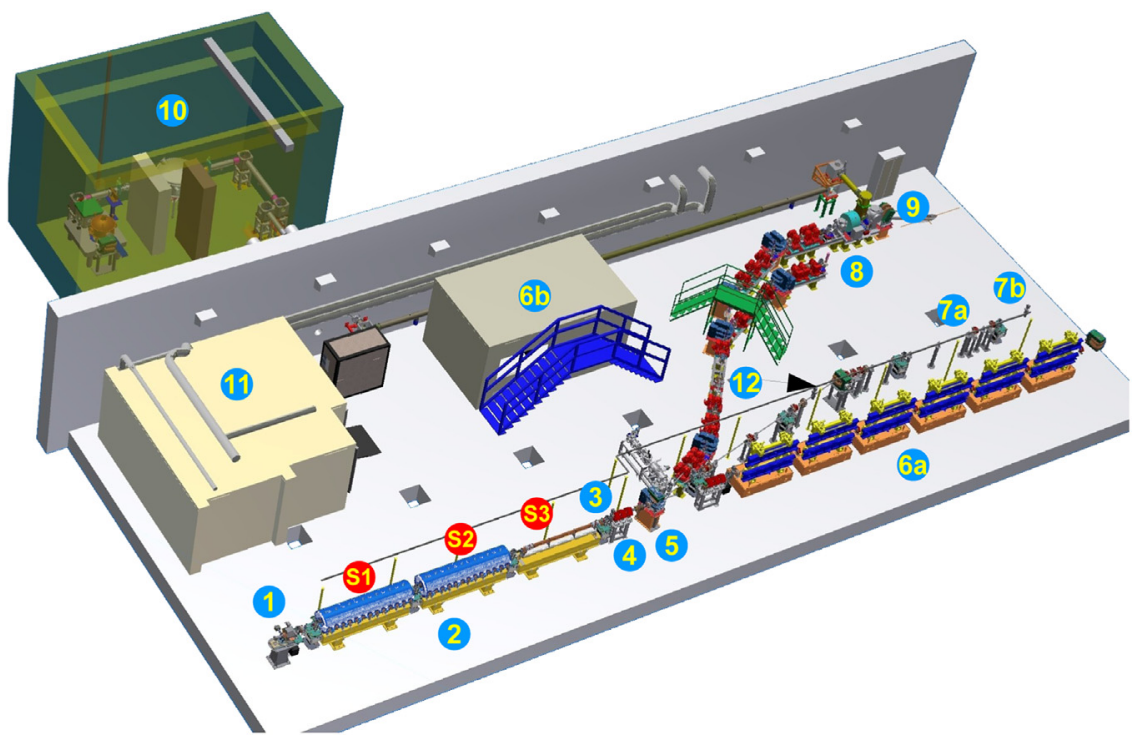

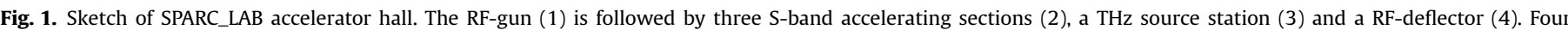

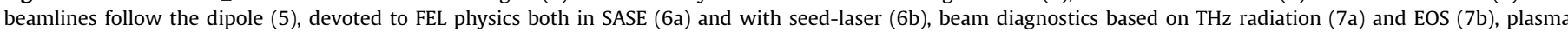

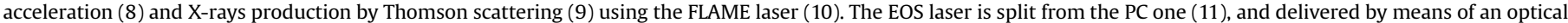
transfer line (12).

$50 \mathrm{MV} / \mathrm{m}$. Moreover, also the linac of the Gamma Beam System to be built in Magurele (Romania), in the framework of the ELI-NP project [29], is based on strongly damped high repetition rate C-band structures [30,31].

The SPARC_LAB linac original energy upgrade [32] foresaw the replacement of the last $3 \mathrm{~m}$ long low gradient $(13 \mathrm{MV} / \mathrm{m})$ S-band TW section with two identical $1.4 \mathrm{~m}$ long high gradient ( > $35 \mathrm{MV} / \mathrm{m}$ ) C-band TW structures, as schematically represented in Fig. 2. This would have led to an energy gain of almost a factor 3 in the last three meters of the linac, with a final beam energy around $240 \mathrm{MeV}$. Nevertheless, due to the recent beam driven plasma acceleration experiment proposal [33] and the linac spatial constraints, it has been decided to replace the S-band structure with only one C-band section and the plasma experimental chamber, as shown in the mechanical layout of Fig. 3. With this

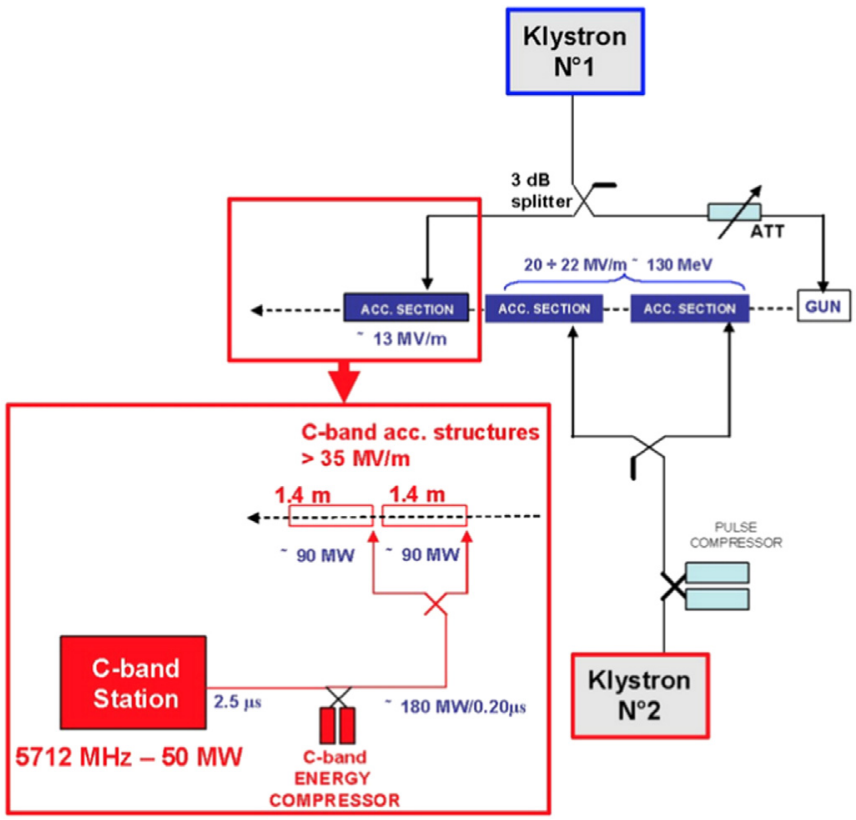

Fig. 2. Sketch of SPARC_LAB RF layout after C-band upgrade, picture courtesy of Alesini et al. [32].

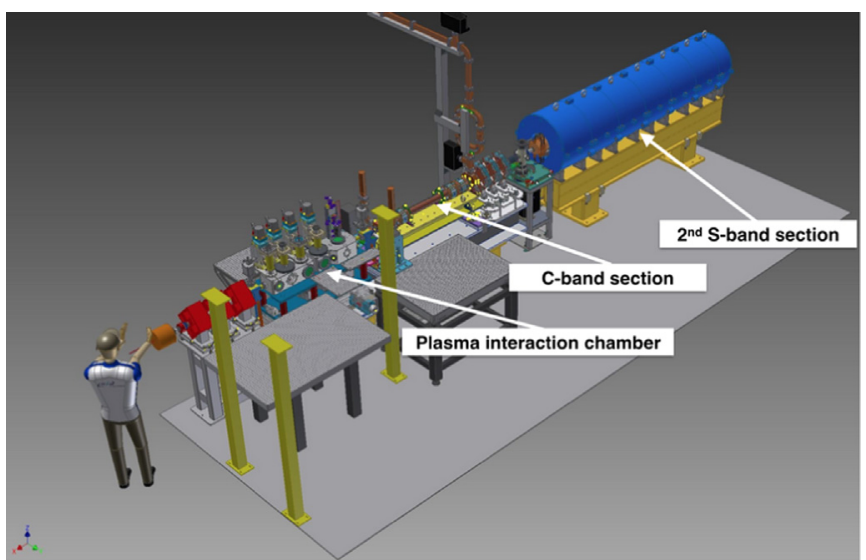

Fig. 3. Sketch of SPARC_LAB linac-end after C-band and plasma interaction chamber installation.

solution the linac output energy will be larger than $180 \mathrm{MeV}$, which is sufficient for the plasma acceleration proof of principle.

The C-band structure is fed with a 50 MW Toshiba ET37202 klystron. The high voltage pulsed modulator and the $400 \mathrm{~W}$ solid state driver amplifier have been manufactured by ScandiNova (Sweden) and Microwave Amplifier (England) respectively. The new system will also include a SKIP-type pulse compressor [34], developed by the Institute of High Energy Physics (IHEP) of Beijing (China), that is currently under commissioning at LNF. The electromagnetic, mechanical and thermal design of the C-band structures has been carried out at LNF-INFN laboratories [32] with the support of a private company (COMEB [35]) for their production. Prior to the realization of the final structures, a prototype with a reduced number of cells has been manufactured and highpower tested at KEK (Japan). The maximum gradient that has been reached is $50 \mathrm{MV} / \mathrm{m}$ with a breakdown rate (BDR) per unit length of $\approx 10^{-6}$ in units of breakdowns/pulse/meter, as thoroughly reported in [32]. In light of the results achieved at KEK, a conservative estimation of the C-band structure obtainable gradient can be made assuming $50 \mathrm{MV} / \mathrm{m}$ as peak electric field in the first cell of the structure, with a uniform RF input pulse as example. This corresponds to an average gradient larger than $43 \mathrm{MV} / \mathrm{m}$, 
keeping the machine in stable operation ( $\mathrm{BDR}<10^{-6}$ breakdowns/ pulse/m).

In the first section of the paper the design criteria and the detailed description of the mechanical realization of the structures will be presented. In section two we report the results of the low and high power RF tests, including the tuning procedure. Finally, in the last section of the paper, we describe the low level RF (LLRF) system developed at PSI in the framework of TIARA project [36], which has been successfully installed and integrated in SPARC_LAB control system for C-band structures operation.

\section{Structure design and fabrication}

SPARC_LAB C-band structures have been designed by LNF-INFN laboratories with the support of COMEB for their manufacture. The detailed description of the electromagnetic project of these sections is given in [32]. The final geometrical and electromagnetic parameters have been summarized in Table 1.

The structures are TW and constant impedance (CI) with symmetric waveguide couplers. The coupler design is based on the research carried out at SLAC on "low pulsed heating" X-band couplers for high gradient operation [37]. The input coupler includes a waveguide splitter, while the output one has two symmetric ports connected to two RF loads.

The C-band structure design has been optimized for operation with an RF pulse compressor. In fact, large irises have been employed to limit surface electric fields. Large irises also provide higher pumping speeds, which are convenient in case of vacuum level worsening due to RF breakdown. Additionally, this choice increases the group velocity and consequently reduces the filling time, such that shorter pulses can be fed to the section. The choice of a CI structure has been made mainly to reduce the fabrication cost (since all the cells are identical) at the expenses of a decreasing accelerating gradient along the section. SPARC_LAB linac, however, works in single bunch mode, and such decay of the field profile could be partially compensated by the exponential rise of a SLED pulse. The result is a nearly constant gradient profile with a $10 \%$ field increase at the end of the structure, due to the combined effect of the pulse compressor and the $\mathrm{CI}$ design.

The mechanical drawing of the structure is reported in Fig. 4. Each cell, shaped as a cup to include a single iris, has been realized

Table 1

SPARC_LAB C-band structures main design parameters. *After 1 filling time, $\mathrm{V}_{\text {acc }}^{\text {avg }}=35 \mathrm{MV} / \mathrm{m}$; **after 1 filling time, $\mathrm{V}_{\text {acc }}^{\text {avg }}=35 \mathrm{MV} / \mathrm{m}$ at $10 \mathrm{~Hz}$.

\begin{tabular}{|c|c|}
\hline Parameter & Value \\
\hline Frequency & $5.712 \mathrm{GHz}$ \\
\hline Phase advance per cell & $2 \pi / 3 \mathrm{rad}$ \\
\hline Number of accelerating cells $(\mathrm{N})$ & 71 \\
\hline Structure length including couplers (L) & $1.4 \mathrm{~m}$ \\
\hline Cell length $(\mathrm{d})$ & $17.495 \mathrm{~mm}$ \\
\hline Iris radius $(a)$ & $7 \mathrm{~mm}$ \\
\hline Outer radius $(b)$ & $21.13 \mathrm{~mm}$ \\
\hline Normalized group velocity $\left(v_{g}\right)$ & $0.02831 / \mathrm{c}$ \\
\hline Field attenuation $(\alpha)$ & $0.2061 / \mathrm{m}$ \\
\hline Series impedance & $34.1 \mathrm{M} \Omega$ \\
\hline Shunt impedance & $82.8 \mathrm{M} \Omega / \mathrm{m}$ \\
\hline Filling time $\left(\mathrm{t}_{F}\right)$ & $150 \mathrm{~ns}$ \\
\hline Minimum average accelerating gradient $\left(\mathrm{V}_{a c c}^{a v g}\right)$ & $>35 \mathrm{MV} / \mathrm{m}$ \\
\hline Max. peak surf. electric field* & $80 \mathrm{MV} / \mathrm{m}$ \\
\hline Max. peak surf. magnetic field* & $92 \mathrm{kA} / \mathrm{m}$ \\
\hline Max. modified Poynting vector* & $0.88 \sqrt{\mathrm{MW} / \mathrm{mm}^{2}}$ \\
\hline Output power & $0.6 \mathrm{P}_{\text {in }}$ \\
\hline Average dissipated power** & $59.6 \mathrm{~W}$ \\
\hline Pulsed heating** & $<1{ }^{\circ} \mathrm{C}$ \\
\hline
\end{tabular}

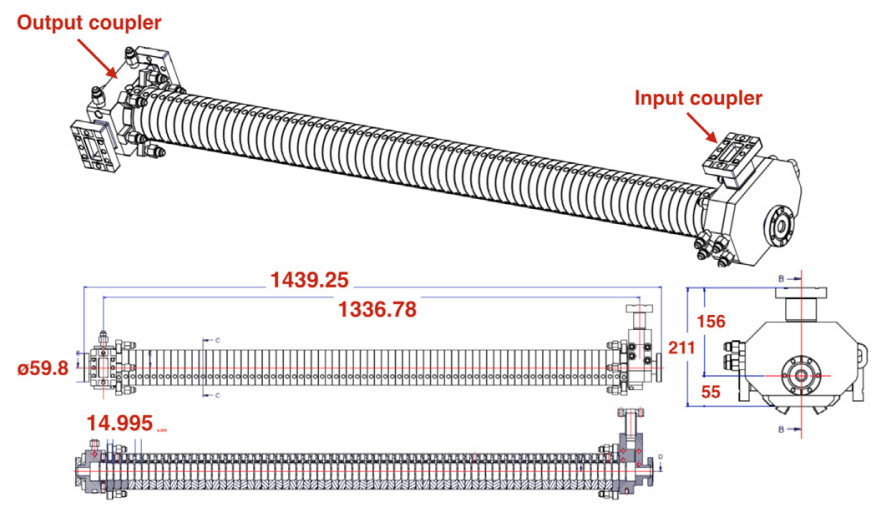

Fig. 4. Mechanical drawing of SPARC_LAB C-band structures (dimensions in mm).

with a high precision turning machine. It houses three tuners, placed around the cell at $120^{\circ}$, able to deform the outer wall in both directions, as shown in Fig. 5 (right). The integrated cooling system employs six cooling pipes that run longitudinally along the whole structure, as shown in Fig. 5 (left). The main issues of the fabrication phase have been the mechanical tolerances and the internal surface finishing. These fabrication specifications are critical to ensure high-gradient performance of the structure. Finally, a surface roughness lower than $50 \mathrm{~nm}$ and an absolute dimension accuracy in the $\pm 2 \mu \mathrm{m}$ range have been obtained by means of diamond tooling.

Input and output couplers were manufactured by milling a single copper ingot with a computer controlled machine (roughness $<200 \mathrm{~nm}$; precision in all the dimensions $\pm 10 \mu \mathrm{m}$ ), as reported in Figs. 6 and 7. Then the input-output flanges have been brazed together with a blank copper plate to close the structure. Before the brazing process, shown in Fig. 8, all copper elements (cells and couplers) have been cleaned with ALMECO-19 followed by a mixture of citric acid (concentration $5 \mathrm{~g} / \mathrm{l}$ ) and distilled water in ultrasound bath. The cells have been joined in two stacks and then one half-structure at a time has been brazed, for the whole section could not fit the LNF oven.

The brazing procedure of the two cell stacks has been very delicate (due to the difficulty to preserve the alignment during brazing at high temperature), and it has been necessary to repeat it twice before success. In fact, a strong field reflection was measured after the first attempt, probably due to a poor RF contact of the two junction cells. To this regard, the structure has been cut apart and the mechanical design of the central junction has been modified, as shown in Fig. 9. Finally, the stacks have been successfully brazed together in COMEB horizontal oven, held in place by custom-made supports.

Satisfactory results have been obtained using the same technical solutions for the second section structure as well. The whole brazing procedure has been done in four steps using four different alloys at different temperatures: palcusil 15, palcusil 10, palcusil 5 and incusil. The first alloy has been used to braze the stainless steel components (flanges and cooling pipe tubes) on copper parts (waveguide couplers and first cells adjacent to the couplers), the second one to braze the coupler and a stack of 35 cells separately, the third to braze the other coupler and cell stack together and the last for the central junction. The two structures and all the intermediate sub-components have been vacuum tested with a sensitivity lower than $5 \times 10^{-10} \mathrm{mbar} \mathrm{l} / \mathrm{s}$ with a He leak detector. The final structures have also been baked out at $110^{\circ} \mathrm{C}$ for $24 \mathrm{~h}$, reaching a final pressure in the high power installation setup of the order of $5 \times 10^{-10}$ mbar. 

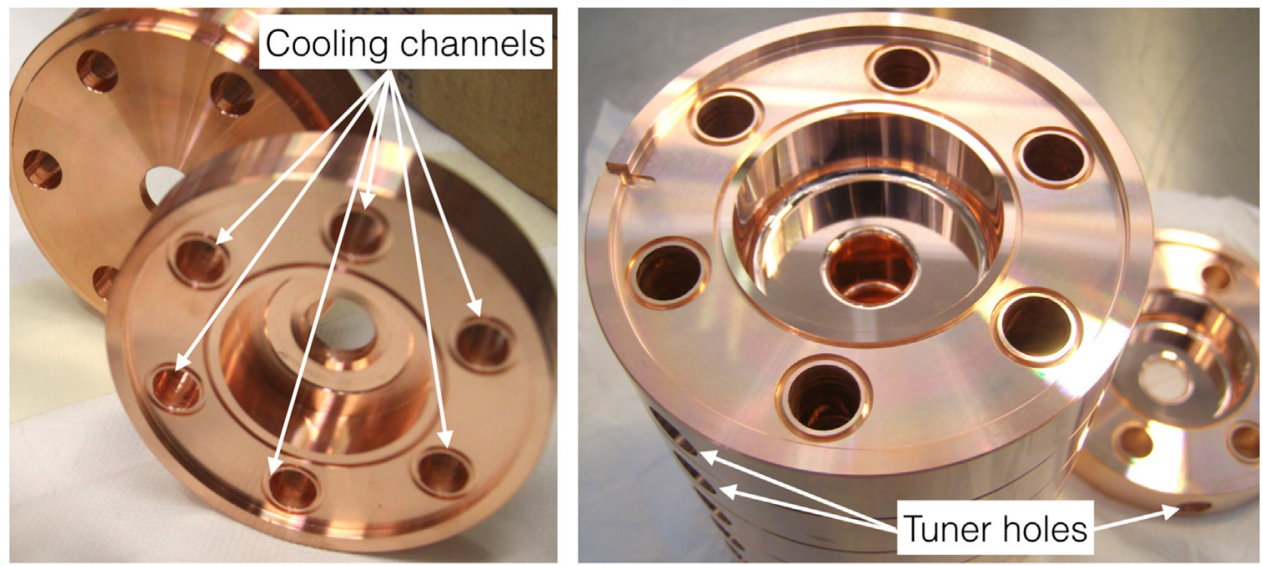

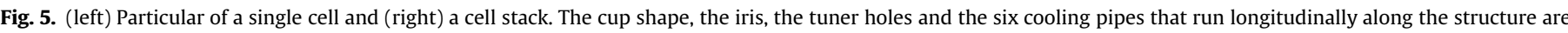
highlighted.

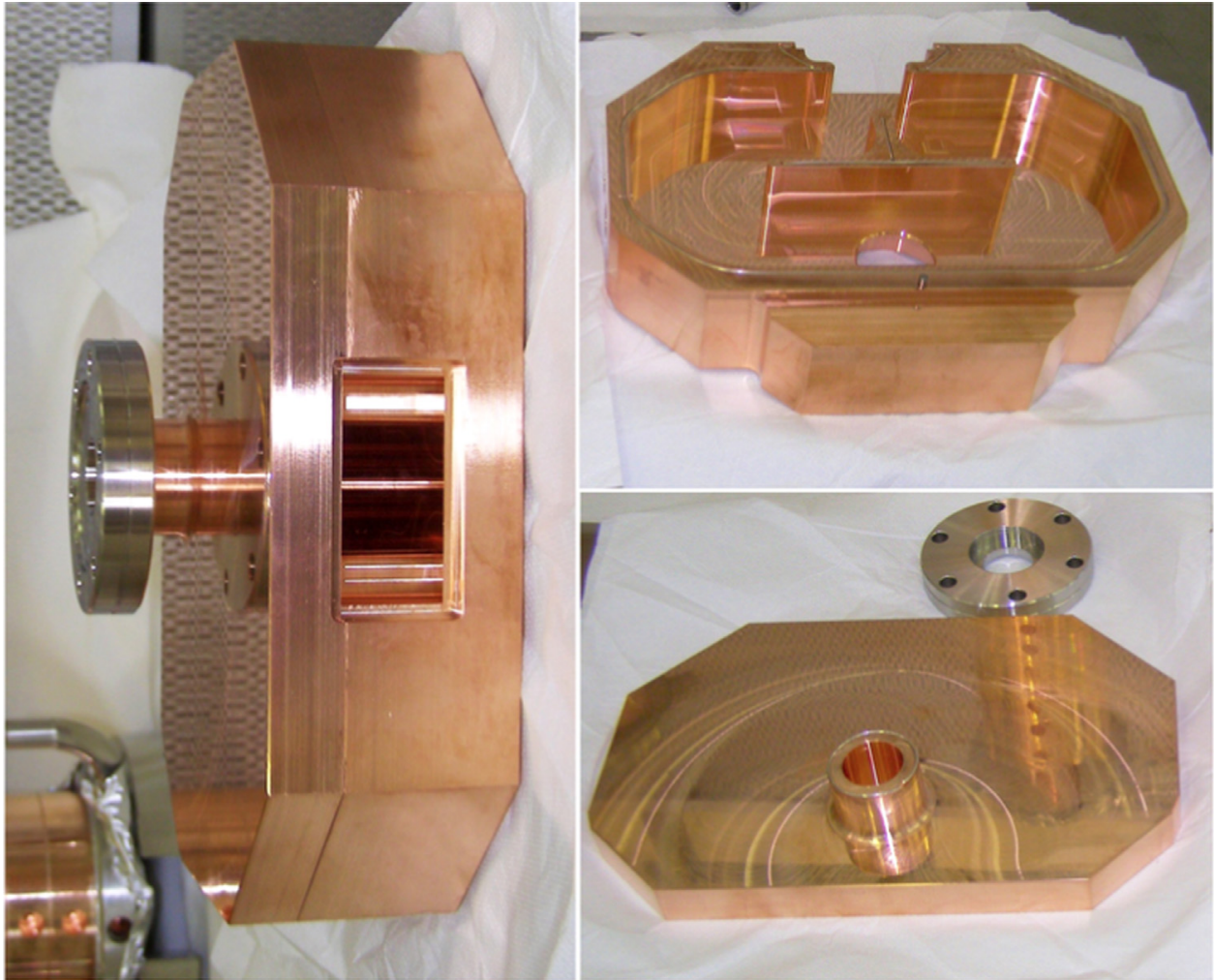

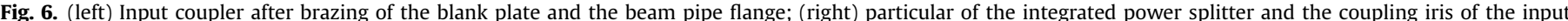
coupler before the brazing process.

\section{Low and high power test results}

After the structure realization, low-power RF tests and structure tuning have been performed at LNF laboratories. The measurement of the electric field inside the structures and the tuning have been done using the bead-pull technique, following the approach described in [38]. A picture of the structure under tuning is shown in Fig. 10. The electric field profile after tuning is reported in Figs. 11 and 12 for the first and second section respectively, while the electric field phase advance has been measured and shown in Fig. 13 only for the second structure. Comparable results have been obtained for the first section as well. In order to estimate the electric field flatness ( $f f$ ), an exponential fit to the field profile shown in Figs. 11 and 12 has been performed, such that: $f f(i)=\frac{E_{f i t}-E_{\text {meas }}(i)}{E_{\text {meas }}(i)}$

where $E_{\text {meas }}(i)$ is the amplitude (in arbitrary units) of the i-th measured field peak and $E_{f i t}$ is the amplitude of the exponential fit function relative to the longitudinal coordinate of the i-th peak: $E_{\text {fit }}=E_{0} \exp \left(-\alpha \cdot z_{\text {meas }}(i)\right)$. Under this assumption, the rms of the field flatness distribution can be used as estimation of the field uniformity. For the first section a $f f_{r m s}=1.3 \%$ has been measured (with maximum and minimum values of $2.9 \%$ and $-3 \%$ ), while $f f_{r m s}=1.9 \%$ has been obtained for the second structure (with maximum and minimum values of $3.5 \%$ and $-2.6 \%$ respectively). Both results are comparable with simulations ( $f f_{\text {sim }}= \pm 3 \%$ ).

The reflection coefficient $\left(S_{11}\right)$ obtained from the EM simulation was $-25 \mathrm{~dB}$. Once the tuning procedure has been completed, a $S_{11}$ 

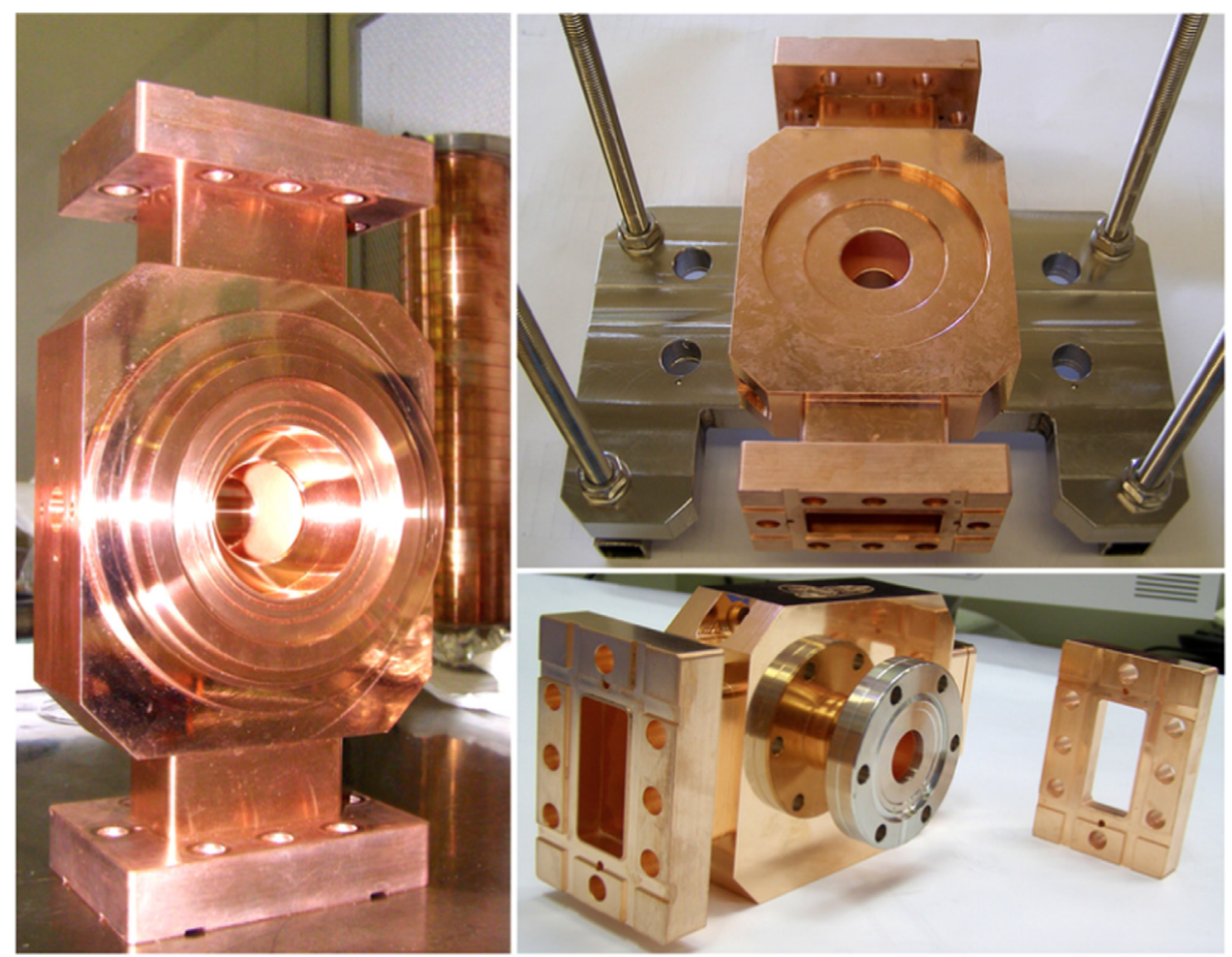

Fig. 7. Particular of various brazing stages of the output coupler.
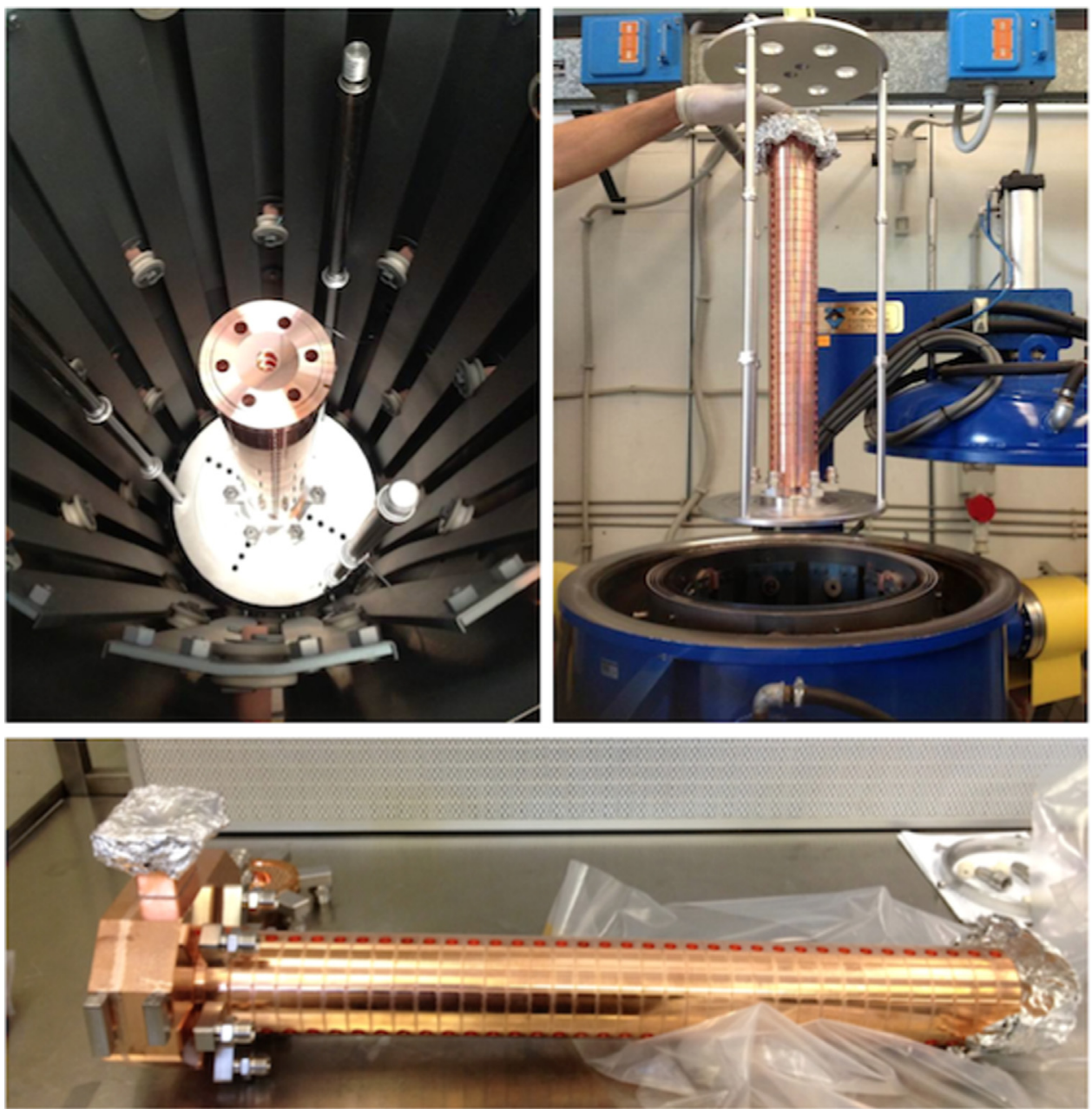

Fig. 8. (top-left, right) Brazing of the first cell stack; (bottom) first half of the C-band structure with input coupler brazed. 

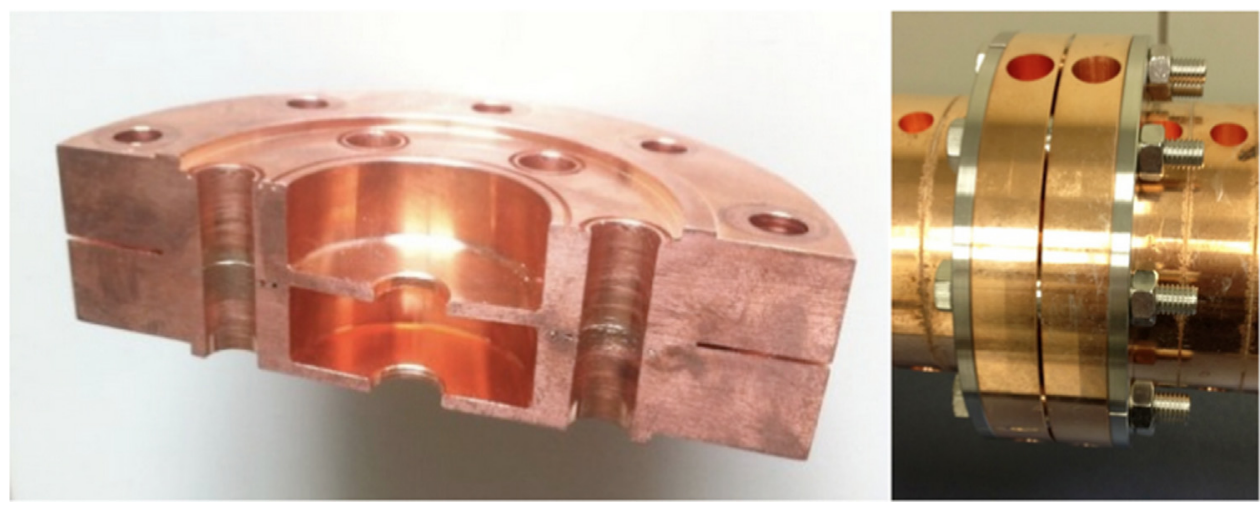

Fig. 9. (left) Prototype of the new junction between the two half structures. (right) The two central cells ready for brazing held in place by custom supports.

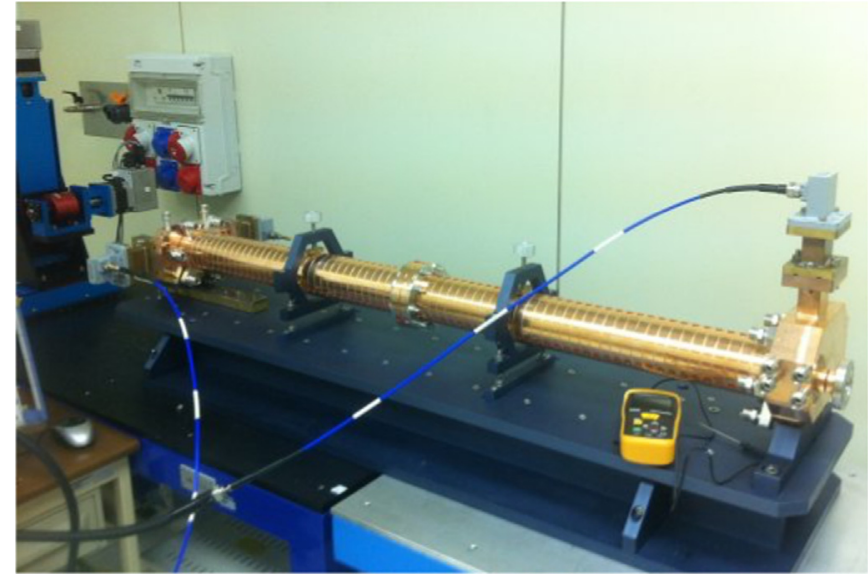

Fig. 10. Tuning of the first C-band structure at LNF.

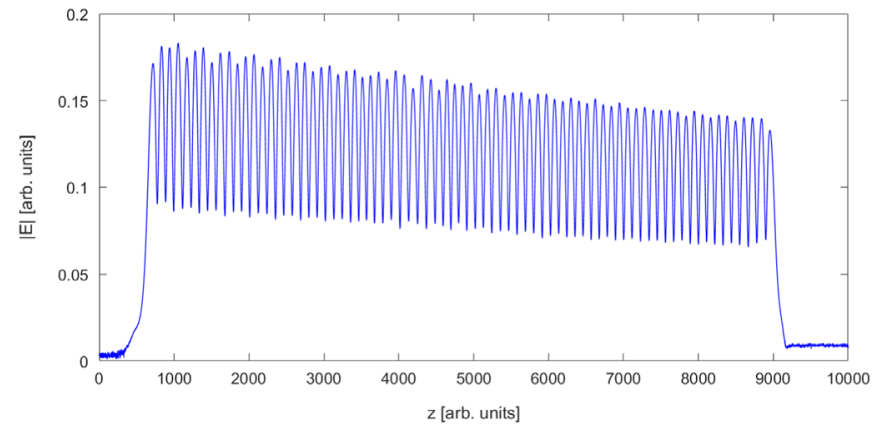

Fig. 11. Measured electric field profile after tuning of the first C-band structure.

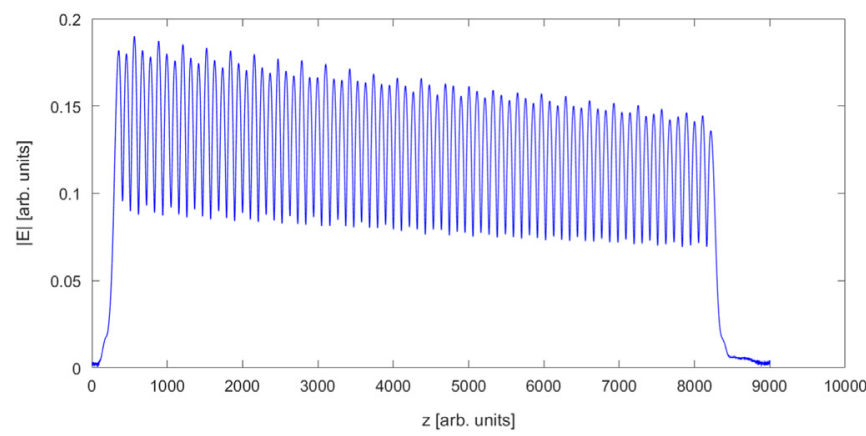

Fig. 12. Measured electric field profile after tuning of the second C-band structure.

lower than $-27 \mathrm{~dB}$ has been measured at the nominal working frequency for the second structure. This has been reported in Fig. 14, together with the transmission coefficients measured at

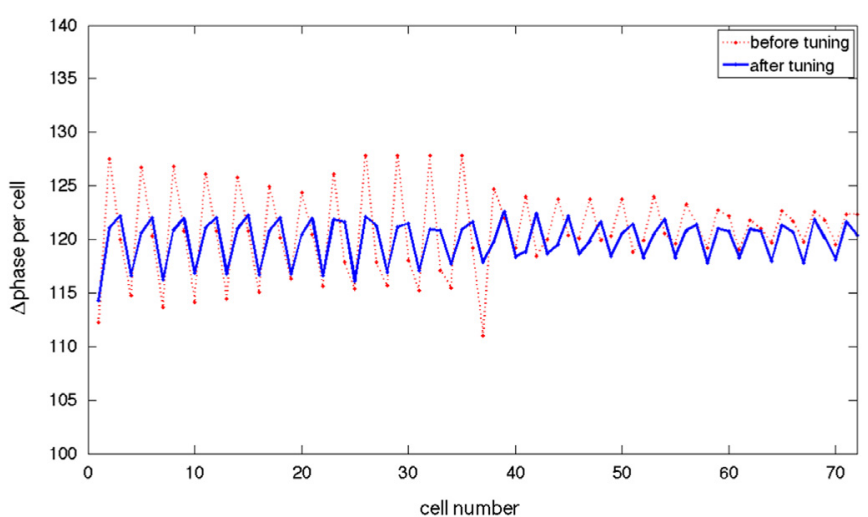

Fig. 13. Phase advance of the electric field inside the second accelerating structure before (dashed) and after (solid) tuning procedure. A slight perturbation of the phase advance in correspondence of the central junction can be observed in the red plot. This small effect has been completely compensated after the tuning procedure. The design value is $120^{\circ}$, comparable results have been obtained for the first section as well.
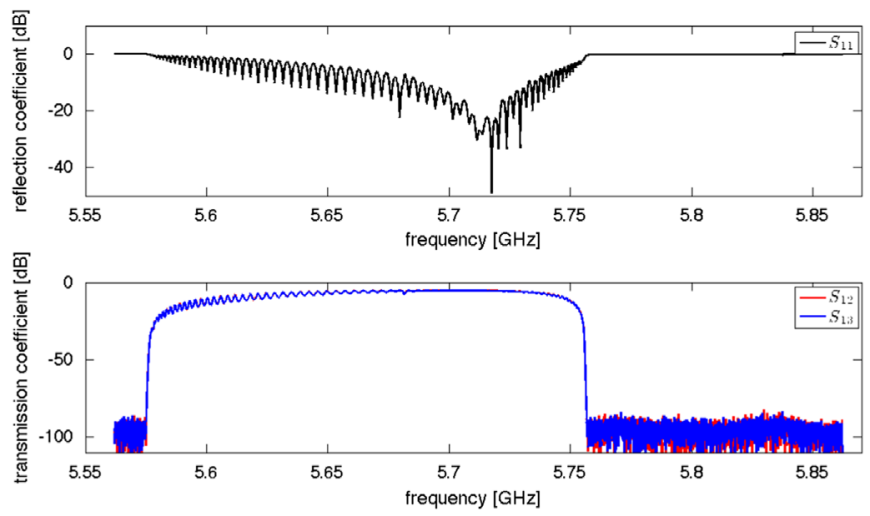

Fig. 14. Reflection coefficient measured at the input port after tuning (top - black); transmission coefficients measured at both output ports after tuning (bottom - red blue) of the second C-band structure. (For interpretation of the references to color in this figure legend, the reader is referred to the web version of this article.)

\section{Table 2}

Simulated and measured scattering parameters for the two C-band sections. From the transmission coefficients $\left(S_{12}, S_{13}\right)$ the power attenuation has been calculated and compared to simulation. A very good agreement has been found for structure \#2, while a slightly higher attenuation has been measured for structure \#1.

\begin{tabular}{llll}
\hline Parameter & Simulation & Structure \#1 & Structure \#2 \\
\hline $\mathrm{S}_{11}$ & $-25 \mathrm{~dB}$ & $-21 \mathrm{~dB}$ & $-27.4 \mathrm{~dB}$ \\
$\mathrm{~S}_{12} / \mathrm{S}_{13}$ & $-5.22 \mathrm{~dB}$ & $-5.44 \mathrm{~dB}$ & $-5.23 \mathrm{~dB}$ \\
Output power & $0.6 \mathrm{P}_{\text {in }}$ & $0.57 \mathrm{P}_{\text {in }}$ & $0.598 \mathrm{P}_{\text {in }}$ \\
\hline
\end{tabular}




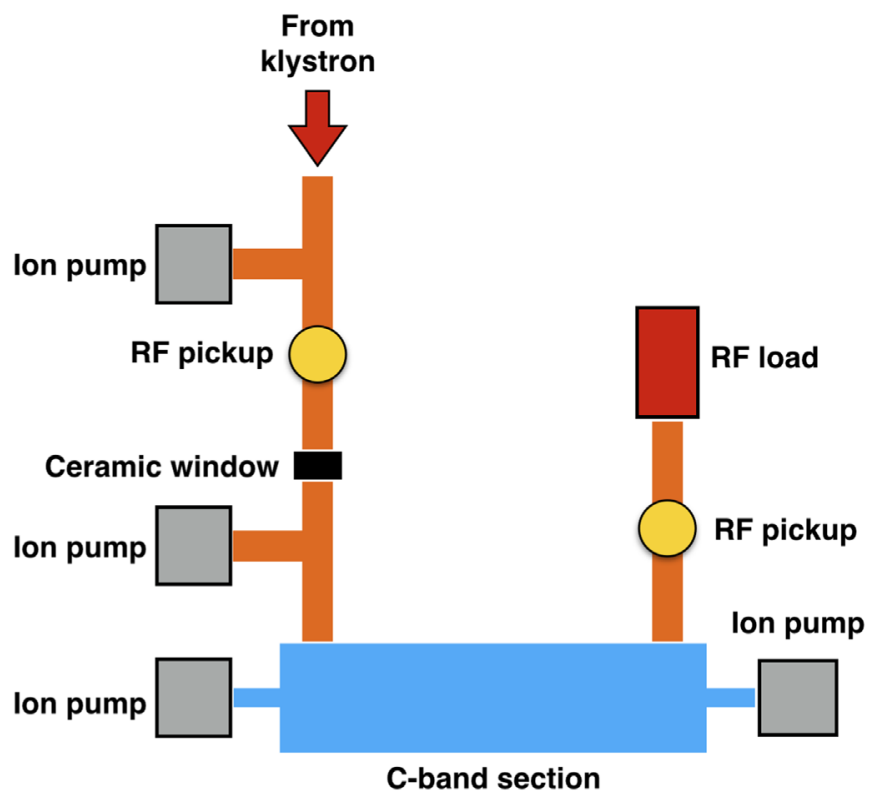

Fig. 15. Sketch of the high power test setup.

both output coupler ports $\left(\mathrm{S}_{12}, \mathrm{~S}_{13}\right)$. For the first structure, instead, a reflection coefficient of $-21 \mathrm{~dB}$ has been measured, probably due to the brazing issues encountered during its realization. Even though this value does not comply with the simulations, we believe this difference should not be critical during the operation of the machine. Moreover, from the $S_{12}$ and $S_{13}$ measurement the power attenuation along the structure has been calculated. This is in very good agreement with the simulation, even though a slightly higher attenuation has been measured for the first section, probably for the same brazing issues mentioned before. Table 2 summarizes simulated and measured reflection and transmission coefficient for both structures.

The installation of the first structure at SPARC_LAB for the high power test conditioning took place in October 2013. A schematic sketch of the experimental setup, together with its installation in the SPARC_LAB bunker, are shown in Figs. 15 and 16 respectively. Three ion pumps have been employed to guarantee a good vacuum performance of the system: one after the ceramic window of the

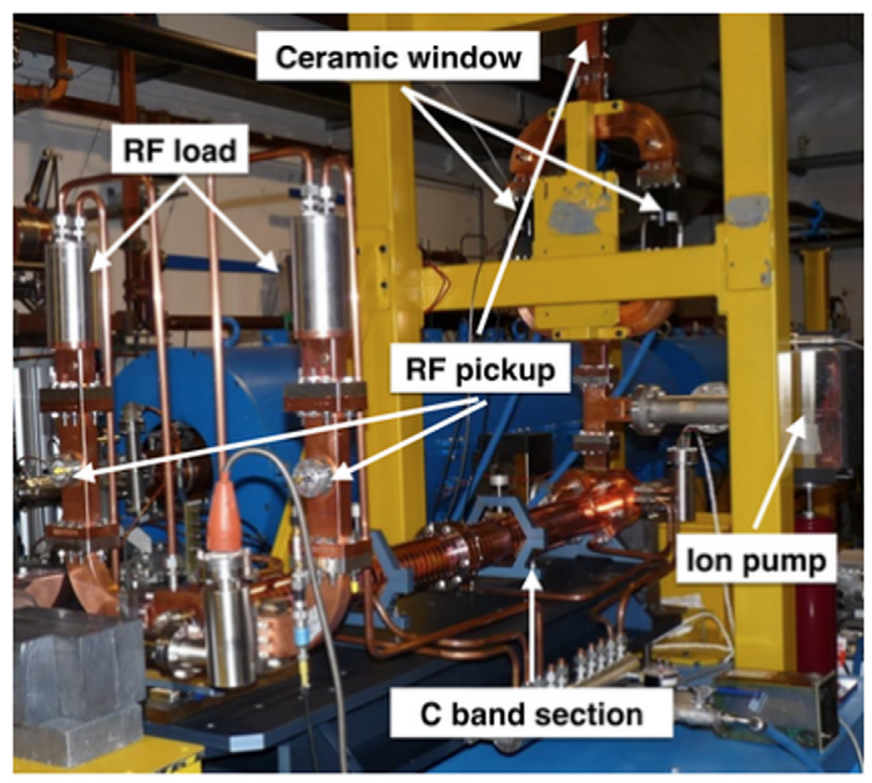

Fig. 16. High power test stand installation in the SPARC_LAB bunker. waveguide network and two connected to the beam-pipe. The RF signals have been detected by means of three RF pickups: the first has been placed before the power splitter, while the other two have been installed on each output waveguide. At the end of the structure two matched RF water-loads (CML 4530-02, conditioned at $50 \mathrm{MW}$ peak power, $2.5 \mu \mathrm{s}, 10 \mathrm{~Hz}$ ) dissipate the output RF power.

The RF conditioning procedure has been carried out in three steps: (i) test of the klystron system terminated into a load; (ii) test of the waveguide network terminated into a load up to the SPARC_LAB hall; (iii) test of the accelerating structures.

The high power test of the first section started in November 2013. The nominal pulse repetition rate was $10 \mathrm{~Hz}$ with a pulse duration of 165 ns (slightly longer than the filling time, so to reach maximum stored energy within the structure). The klystron power has been increased changing the high voltage of the modulator at a constant RF input level. The currents of the ion pumps and the RF signals from pickups (driver forward, klystron forward, section IN forward/reverse) have been monitored throughout the process to identify any discharge event. An example of the control interface used during the commissioning of the two accelerating structures is shown in Fig. 17, where a typical discharge event, characterized by a spike in the vacuum pressure chart, has been recorded.

The conditioning procedure was semi-automatic. The high voltage of the modulator could be interlocked in three cases: (i) forced by operators; (ii) exceeding the threshold on current absorption (set to $50 \mu \mathrm{A}$, corresponding to a vacuum pressure of $10^{-7}$ mbar) of any ion pump along the network and C-band structure; (iii) automatically by klystron interlocks (tube vacuum, modulator interlocks). Under normal operating conditions the vacuum pressure has been kept between $5 \cdot 10^{-10} \mathrm{mbar}$ and $2 \cdot 10^{-9}$ mbar.

The RF conditioning of the first section lasted about $155 \mathrm{~h}$ with approximately $5.5 \cdot 10^{6} \mathrm{RF}$ pulses being delivered to the structure. It has been performed keeping fixed the repetition rate and pulse length at nominal values ( $10 \mathrm{~Hz}$ and $165 \mathrm{~ns}$ respectively) and increasing the input power as the structure was conditioned at different gradient levels. During RF conditioning no pulse compressor has been used, since it has been acquired later, and hence the klystron output power has been limited to $45 \mathrm{MW}$ for safe operation. With such configuration, the maximum power at the input port of the section is $38 \mathrm{MW}$, not sufficient to achieve an average gradient larger than $32 \mathrm{MV} / \mathrm{m}$. For this preliminary phase, the target BDR has been set lower than $4 \cdot 10^{-5}$ breakdown/pulse/m. This value corresponds to about 2 breakdowns per h which, considering the much higher RF-Gun BDR at SPARC_LAB (at least of a factor 5), will produce a negligible effect on the machine stability.

Satisfactory results have been obtained: $38 \mathrm{MW}$ input power in the structure (44 MW from the klystron); peak accelerating field of $36 \mathrm{MV} / \mathrm{m}$ (average along the structure of $32 \mathrm{MV} / \mathrm{m}$ ); a breakdown rate lower than $2 \cdot 10^{-5}$ breakdown/pulse $/ \mathrm{m} ; 340 \mathrm{kV}$ modulator high voltage. A plot showing the conditioning progress is shown in Fig. 18. The RF conditioning of the second structure began on late December 2013 and was concluded on February 2014 with similar results. Considering the limited number of pulses delivered to the structures (lower than $6 \cdot 10^{6}$ ), an extensive conditioning campaign has been scheduled as soon as the installation and commissioning of the SLED are completed.

\section{Low level RF system}

A flexible LLRF system has been designed and manufactured at PSI for C-band operation control at SPARC. Its main design goals have been a high phase readout resolution $(<15 \mathrm{fs}$ ) and a signal 

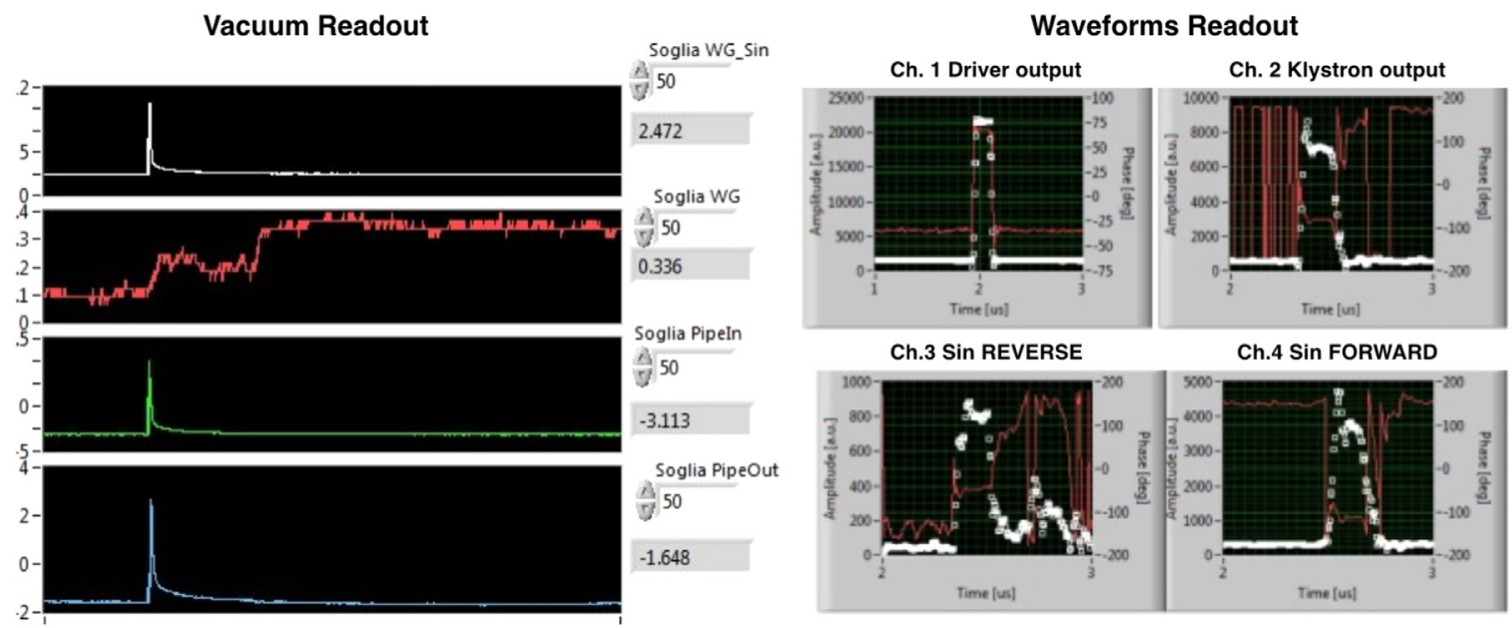

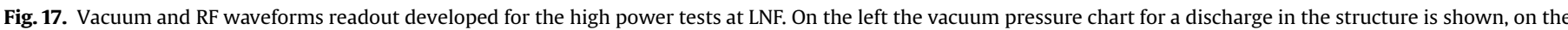

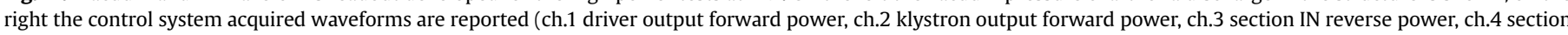
IN forward power).

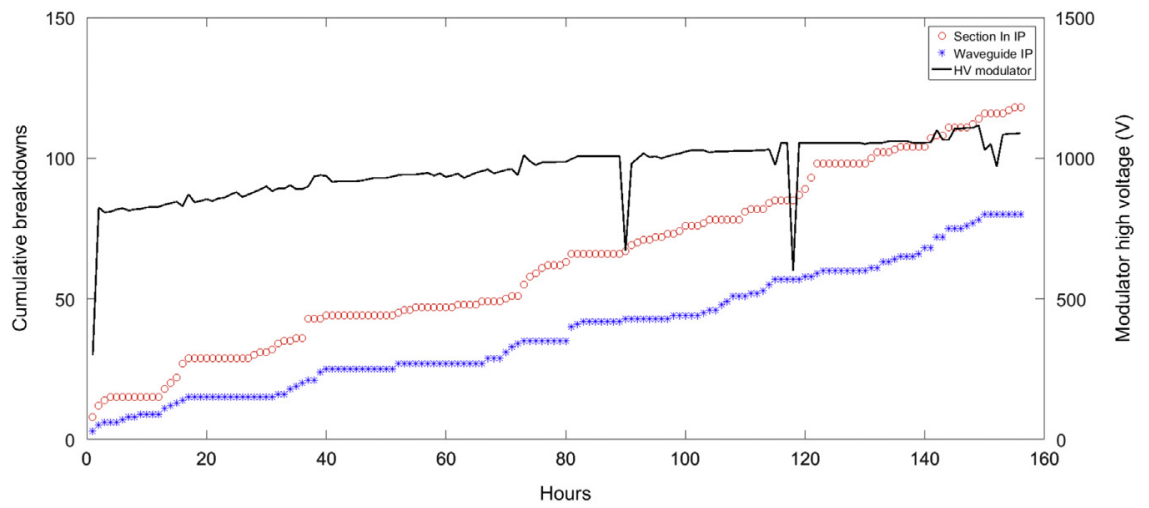

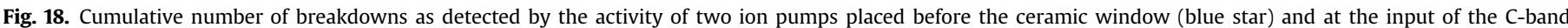

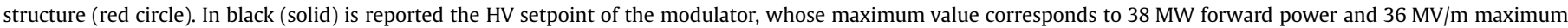
gradient at the entrance of the section. After $155 \mathrm{~h}$ a BDR of $1.5 \cdot 10^{-5}$ has been reached.

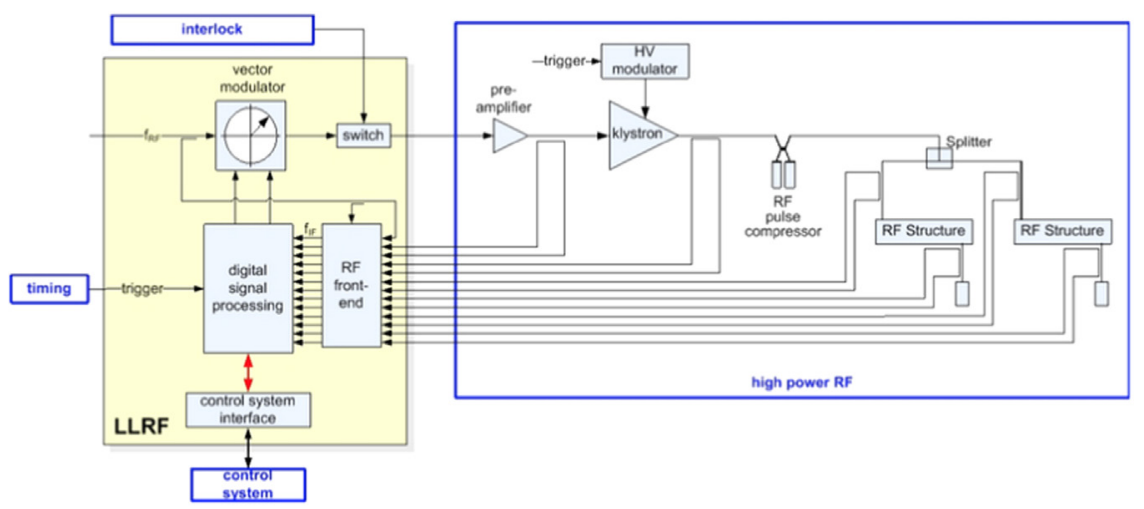

Fig. 19. Sketch of SPARC_LAB C-band LLRF system, RF power unit and waveguide distribution.

digital processing capability (by means of FPGA) that allows an arbitrary shaping of the RF output pulse amplitude and phase. The project followed a modular approach based on three main analog blocks: (i) a base-band vector modulator, that provides the required rotation and correction for the $5.712 \mathrm{GHz}$ reference which is fed to the pre-amplifier of the klystron; (ii) an RF multi-channel receiver and (iii) a local oscillator (LO) generation unit, that produces the intermediate frequency from the 144th sub-harmonic of the RF reference and the LO signal. A schematic view of the LLRF system has been reported in Fig. 19.

All the C-band RF signals are down-converted to an intermediate frequency $\left(f_{I F}=39.666 \mathrm{MHz}\right)$. They are then digitized by means of commercially available FPGA Mezzanine Cards (FMC) A/D modules. Once the data is digitally demodulated on several VME64x FPGA/PowerPC processing boards, I/Q amplitude and phase information can be transferred to SPARC_LAB control system. Amplitude and phase output waveforms can be arbitrarily set by a digital high level control system application and transmitted 


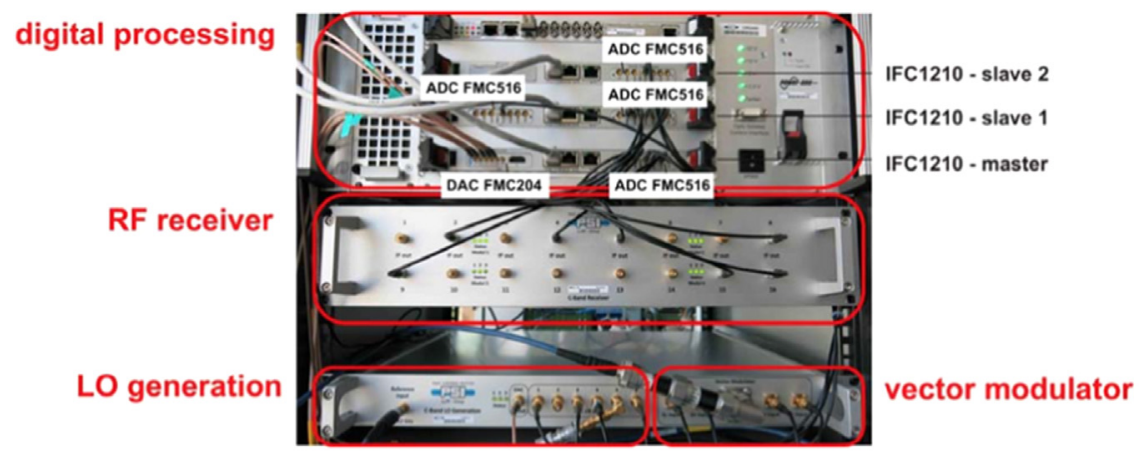

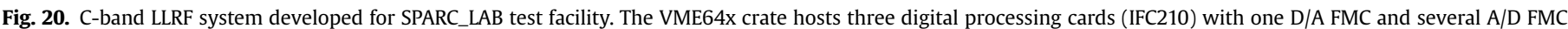

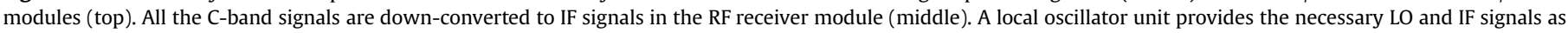

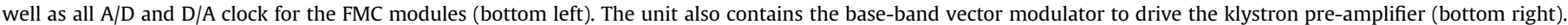

back to the LLRF processing board. They are then converted to analog base-band signals by a fast FMC D/A module that drives the vector modulator. A picture of the LLRF system installed at SPARC_LAB is shown in Fig. 20.

The LLRF integration into SPARC_LAB control system has been successfully done implementing an EPICS/LabVIEW interface using EPICS CA drivers, which are fully compatible with SPARC_LAB control system. The high power test of the second C-band section have been performed using this interface, which also includes the readout of the vacuum pumps (placed along the waveguide network) and the RF power station control.

\section{Conclusions}

In this paper we presented the realization, the tuning, low and high power tests of the two high gradient C-band structures that were originally designed for SPARC_LAB linac energy upgrade. Due to beam driven plasma acceleration experiments planned at SPARC_LAB and to the limited free space available, just one section has been installed at the end of SPARC_LAB linac, together with a plasma interaction chamber. A detailed description of the mechanical realization has been given, with a particular emphasis on the solutions adopted to overcome the problems arisen during the brazing process. The final layout, in fact, foresees a special junction to connect two pre-brazed half structures. Satisfactory results have been obtained after low and high power tests performed at LNF. The phase advance per cell after tuning is $120 \pm 3^{\circ}$, with a cumulative phase error within $\pm 3^{\circ}$. After a preliminary conditioning phase (without any pulse compressor installed and only $5.5 \cdot 10^{6} \mathrm{RF}$ pulses delivered to the structures), an average accelerating gradient of $32 \mathrm{MV} / \mathrm{m}(36 \mathrm{MV} / \mathrm{m}$ peak) has been reached at nominal working conditions $(10 \mathrm{~Hz}$ repetition rate, $165 \mathrm{~ns}$ pulse length, $340 \mathrm{kV}$ modulator high voltage) with a BDR lower than $2 \cdot 10^{-5}$ breakdowns $/ \mathrm{m} \cdot \mathrm{s}$ for both sections. According to the preliminary test results, the gradient reached so far allows to reach a total accelerating voltage of $45 \mathrm{MV}$, whereas the old S-band granted $39 \mathrm{MV}$. Thus, the use of C-band technology will also allow to free some space along the beamline for the plasma interaction chamber installation. The impact of the breakdown rate reached so far on the machine operation will be negligible, if compared to the much larger BDR routinely measured for the RF-Gun. Moreover, considering the limited number of pulses delivered to the structures, compared to what has been done with the section prototype at KEK and in other laboratories [26,28], the obtained results are very promising in view of the full commissioning of the whole C-band RF system.

\section{Acknowledgments}

The research leading to these results has been funded by the European Commission under the FP7-INFRASTRUCTURES-2010-1 project TIARA [Grant agreement no. 261905] and by the Seventh Framework Programme [Grant agreement no. 215840-2]. The authors would like to thank Simone Bini for the technical support during the installation of the structures at SPARC_LAB.

\section{References}

[1] SPARC_LAB website. (last accessed 20/07/2016). 〈http://www.Inf.infn.it/accel eratori/sparc lab/>.

[2] D. Alesini, S. Bertolucci, M. Biagini, C. Biscari, R. Boni, M. Boscolo, M. Castellano, A. Clozza, G.D. Pirro, A. Drago, A. Esposito, M. Ferrario, V. Fusco, A. Gallo, A. Ghigo, S. Guiducci, M. Incurvati, P. Laurelli, C. Ligi, F. Marcellini, M. Migliorati, C. Milardi, L. Palumbo, L. Pellegrino, M. Preger, P. Raimondi, R. Ricci, C. Sanelli, F. Sgamma, B. Spataro, M. Serio, A. Stecchi, A. Stella, F. Tazzioli, C. Vaccarezza, M. Vescovi, C. Vicario, M. Zobov, E. Acerbi, F. Alessandria, D. Barni, G. Bellomo, I. Boscolo, F. Broggi, S. Cialdi, C. DeMartinis, D. Giove, C. Maroli, V. Petrillo, M. Rome, L. Serafini, E. Chiadroni, G. Felici, D. Levi, M. Mastrucci, M. Mattioli, G. Medici, G. Petrarca, L. Catani, A. Cianchi, A. DAngelo, R.D. Salvo, A. Fantini, D. Moricciani, C. Schaerf, R. Bartolini, F. Ciocci, G. Dattoli, A. Doria, F. Flora, G. Gallerano, L. Giannessi, E. Giovenale, G. Messina, L. Mezi, P. Ottaviani, L. Picardi, M. Quattromini, A. Renieri, C. Ronsivalle, L. Avaldi, C. Carbone, A. Cricenti, A. Pifferi, P. Perfetti, T. Prosperi, V. Albertini, C. Quaresima, N. Zema, The SPARC project: a high-brightness electron beam source at LNF to drive a SASE-FEL experiment, Nucl. Instrum. Methods Phys. Res. A 507 (1-2) (2003) 345-349, http://dx.doi.org/10.1016/ S0168-9002(03)00943-4.

[3] D.T. Palmer, The Next Generation Photoinjector (Ph.D. thesis), Stanford University, 1998

[4] L.A. Gizzi, M.P. Anania, G. Gatti, D. Giulietti, G. Grittani, M. Kando, M. Krus, L. Labate, T. Levato, Y. Oishi, F. Rossi, Acceleration with self-injection for an alloptical radiation source at LNF, Nucl. Instrum. Methods Phys. Res. Sect. B: Beam Interact. Mater. At. 309 (2013) 202-209, http://dx.doi.org/10.1016/j. nimb.2013.01.067.

[5] M. Ferrario, D. Alesini, M. Bellaveglia, M. Benfatto, R. Boni, M. Boscolo, M. Castellano, E. Chiadroni, A. Clozza, L. Cultrera, G. Di Pirro, A. Drago, A. Esposito, L. Ficcadenti, D. Filippetto, V. Fusco, A. Gallo, G. Gatti, A. Ghigo, A. Marinelli, A. Marcelli, C. Marrelli, M. Migliorati, A. Mostacci, E. Pace, L. Palumbo, L. Pellegrino, R. Ricci, U. Rotundo, C. Sanelli, F. Sgamma, B. Spataro, S. Tomassini, C. Vaccarezza, M. Vescovi, C. Vicario, F. Ciocci, G. Dattoli, M. Del Franco, A. Dipace, A. Doria, G. Gallerano, L. Giannessi, E. Giovenale, M. Labat, G. Orlandi, S. Pagnutti, A. Petralia, M. Quattromini, C. Ronsivalle, E. Sabia, I. Spassovsky, V. Surrenti, L. Poletto, F. Frassetto, A. Bacci, I. Boscolo, F. Broggi, F. Castelli, S. Cialdi, C. De Martinis, D. Giove, C. Maroli, V. Petrillo, A. Rossi, L. Serafini, M. Mattioli, M. Petrarca, M. Serluca, L. Catani, A. Cianchi, B. Marchetti, G. Marcus, P. Musumeci, J. Rosenzweig, M. Couprie, M. Rezvani Jalal, Recent results of the SPARC FEL experiments, in: Proceedings of the 2009 Particle Accelerator Conference (PAC 09), Vancouver, Canada, 2009, pp. 3178-3180.

[6] M. Ferrario, D. Alesini, A. Bacci, M. Bellaveglia, R. Boni, M. Boscolo, M. Castellano, E. Chiadroni, A. Cianchi, L. Cultrera, G. Di Pirro, L. Ficcadenti, D. Filippetto, V. Fusco, A. Gallo, G. Gatti, L. Giannessi, M. Labat, B. Marchetti, C. Marrelli, M. Migliorati, A. Mostacci, E. Pace, L. Palumbo, M. Quattromini, C. Ronsivalle, A.R. Rossi, J. Rosenzweig, L. Serafini, M. Serluca, B. Spataro, C. Vaccarezza, C. Vicario, Experimental demonstration of emittance compensation with velocity bunching, Phys. Rev. Lett. 104 (2010) 054801, http://dx. doi.org/10.1103/PhysRevLett.104.054801. 
[7] M. Labat, M. Bellaveglia, M. Bougeard, B. Carré, F. Ciocci, E. Chiadroni, A. Cianchi, M.E. Couprie, L. Cultrera, M. Del Franco, G. Di Pirro, A. Drago, M. Ferrario, D. Filippetto, F. Frassetto, A. Gallo, D. Garzella, G. Gatti, L. Giannessi, G. Lambert, A. Mostacci, A. Petralia, V. Petrillo, L. Poletto M. Quattromini, J.V. Rau, C. Ronsivalle, E. Sabia, M. Serluca, I. Spassovsky, V. Surrenti, C. Vaccarezza, C. Vicario, High-gain harmonic-generation freeelectron laser seeded by harmonics generated in gas, Phys. Rev. Lett. 107 (2011) 224801, http://dx.doi.org/10.1103/PhysRevLett.107.224801.

[8] C. Vaccarezza, D. Alesini, M.P. Anania, M. Bellaveglia, E. Chiadroni, D. Di Giovenale, G. Di Pirro, M. Ferrario, A. Gallo, G. Gatti, R. Pompili, S. Romeo, F. Villa, A. Cianchi, P. Oliva, B. Golosio, M. Gambaccini, P. Cardarelli, G. Di Domenico, P. Delogu, A. Bacci, C. Curatolo, D. T. Palmer, V. Petrillo, A. R. Rossi, L. Serafini, P. Tomassini, A. Giribono, F. Filippi, A. Mostacci, The SPARC LAB Thomson source commissioning, in: Proceedings of the 5th International Particle Accelerator Conference (IPAC 2014), Dresden, Germany, June 2014, pp. 267-270.

[9] E. Chiadroni, A. Bacci, M. Bellaveglia, M. Boscolo, M. Castellano, L. Cultrera, G. Di Pirro, M. Ferrario, L. Ficcadenti, D. Filippetto, G. Gatti, E. Pace, A.R. Rossi, C. Vaccarezza, L. Catani, A. Cianchi, B. Marchetti, A. Mostacci, L. Palumbo, C. Ronsivalle, A. Di Gaspare, M. Ortolani, A. Perucchi, P. Calvani, O. Limaj, D. Nicoletti, S. Lupi, The SPARC linear accelerator based terahertz source, Appl. Phys. Lett. 102 (9) (2013) 094101, http://dx.doi.org/10.1063/1.4794014.

[10] F. Giorgianni, M.P. Anania, M. Bellaveglia, A. Biagioni, E. Chiadroni, A. Cianchi, M. Daniele, M. Del Franco, D. Di Giovenale, G. Di Pirro, M. Ferrario, S. Lupi, A. Mostacci, M. Petrarca, S. Pioli, R. Pompili, V. Shpakov, C. Vaccarezza, F. Villa, Tailoring of highly intense $\mathrm{THz}$ radiation through high brightness electron beams longitudinal manipulation, Appl. Sci. 6 (2) (2016) 56, http://dx.doi.org/ 10.3390/app6020056.

[11] V. Fusco, M. Ferrario, Beam dynamics study of a C-band linac driven FEL with S-band photo-injector, in: Proceedings of the 23rd Particle Accelerator Conference (PAC 09), Vancouver, Canada, May 2009, pp. 3355-3357.

[12] T. Tanaka, T. Shintake, SCSS X-FEL conceptual design report, Tech. rep., RIKEN Harima Institute/SPring-8, Sayo, Japan, 2004.

[13] T. Shintake, H. Tanaka, T. Hara, T. Tanaka, K. Togawa, M. Yabashi, Y. Otake, Y. Asano, T. Fukui, T. Hasegawa, A. Higashiya, N. Hosoda, T. Inagaki, S. Inoue Y. Kim, M. Kitamura, N. Kumagai, H. Maesaka, S. Matsui, M. Nagasono, T. Ohshima, T. Sakurai, K. Tamasaku, Y. Tanaka, T. Tanikawa, T. Togashi, S. Wu, H. Kitamura, T. Ishikawa, T. Asaka, T. Bizen, S. Goto, T. Hirono, M. Ishii, H. Kimura, T. Kobayashi, T. Masuda, T. Matsushita, X. Maréchal, H. Ohashi, T. Ohata, K. Shirasawa, T. Takagi, S. Takahashi, M. Takeuchi, R. Tanaka, A. Yamashita, K. Yanagida, C. Zhang, Stable operation of a self-amplified spontaneous emission free electron laser in the extremely ultraviolet region, Phys. Rev. ST Accel. Beams 12 (2009) 070701, http://dx.doi.org/10.1103/ PhysRevSTAB.12.070701.

[14] T. Shintake, N. Akasaka, K. Bane, H. Hayano, K. Kubo, H. Matsumoto, S. Matsumoto, K. Oide, K. Yokoya, C-band linac RF-system for $\mathrm{e}+\mathrm{e}-$ linear collider, in: Proceedings of the 1995 Particle Accelerator Conference (PAC 95), Dallas, U. S.A., May 1995, pp. 1099-1101.

[15] T. Shintake, The choke mode cavity, Jpn. J. Appl. Phys. 31 (11A) (1992) L1567, http://dx.doi.org/10.1143/JJAP.31.L1567.

[16] R. Ganter, R. Abela, T. Garvey, SwissFEL conceptual design report, Tech. Rep. 10 04, V19, Paul Scherrer Institute, 2011.

[17] R. Zennaro, J. Alex, M. Bopp, H.-H. Braun, A. Citterio, H. Fitze, M. Pedrozzi, J.-Y. Raguin, Conceptual design of the C-band module for SwissFEL, in: Proceedings of the 25th International Linear Accelerator Conference (LINAC 2010), Tsukuba, Japan, September, 2010, pp. 392-394.

[18] K. Akai, H. Koiso, K. Oide, Design progress and construction status of SuperKEKB, in: Proceedings of the 3rd International Conference on Particle accelerator (IPAC 2012), New Orleans, U.S.A., May 2012, pp. 1822-1824.

[19] S. Fukuda, M. Akemoto, M. Ikeda, T. Oogoe, T. Ohsawa, Y. Ogawa, K. Kakihara, H. Katagiri, T. Kamitani, M. Sato, T. Shidara, A. Shirakawa, T. Sugimura, T. Suwada, T. Takenaka, K. Nakao, H. Nakajima, K. Furukawa, H. Honma, T. Matsumoto, S. Michizono, Y. Yano, A. Enomoto, Linac upgrade plan using a C-band system for SuperKEKB, in: 30th Advanced ICFA Beam Dynamics Workshop on High Luminosity e $+\mathrm{e}-$ Collisions $(\mathrm{e}+\mathrm{e}-$ Factories), Stanford, California, October, 2003, WGC05, pp. 1-6.

[20] T. Shintake, HOM free linear accelerator structure using choke mode cavity, in: Proceedings of the 17th Linear Accelerator Meeting, Sendai, Japan, September, 1992, pp. 1-4, (KEK-Preprint-92-66).

[21] T. Shintake, Design of high power model of damped linear accelerating structure using choke mode cavity, in: Proceedings of the 15th Particle Accelerator Conference (PAC 93), Washington, D.C., USA, May, 1993, pp. 10481050. http://dx.doi.org/10.1109/PAC.1993.308688.

[22] H. Matsumoto, T. Shintake, N. Akasaka, K. Watanabe, Low temperature brazing technique for accelerators, in: Proceedings of the 5th European Particle Accelerator Conference (EPAC 96), Sitges, Spain, June 1996, pp. 2011-2013.

[23] H. Matsumoto, T. Shintake, N. Akasaka, Fabrication of the C-band (5712-MHz) choke mode type damped accelerator structure, in: Proceedings of the 19th International Linear Accelerator Conference (LINAC 98), Chicago, USA, August, 1998, pp. 261-263.
[24] T. Shintake, H. Matsumoto, N. Akasaka, M. Yoshida, C. Adolphsen, K. Jobe, D. McCormick, M. Ross, T. Slaton, The first wakefield test on the C-band chokemode accelerating structure, in: Proceedings of the 1999 Particle Accelerator Conference (PAC 99), New York, USA, April 1999, pp. 3411-3413.

[25] T. Inagaki, 8-GeV C-band accelerator construction for XFEL/SPring-8, in: Linea Accelerator Conference (LINAC08), Victoria, Canada, October 2008, pp. 10901094.

[26] T. Inagaki, C. Kondo, H. Maesaka, T. Ohshima, Y. Otake, T. Sakurai, K. Shirasawa, T. Shintake, High-gradient C-band linac for a compact X-ray free-electron lase facility, Phys. Rev. ST Accel. Beams 17 (2014) 080702, http://dx.doi.org/10.1103 PhysRevSTAB.17.080702.

[27] R. Zennaro, J. Alex, H. Blumer, M. Bopp, A. Citterio, T. Kleeb, L. Paly, J.-Y. Raguin, C-band accelerator structure development and tests for the SWISSFEL, in: Proceedings of the 26th International Linear Accelerator Conference (LINAC 2012), Tel Aviv, Israel, September, 2012, pp. 492-494.

[28] R. Zennaro, J. Alex, A. Citterio, J.-Y. Raguin, Measurements and high power test of the first C-band accelerating structure for SWISSFEL, in: Proceedings of the 27th International Linear Accelerator Conference (LINAC 2014), Geneva, Switzerland, September, 2014, pp. 333-335.

[29] O. Adriani, S. Albergo, D. Alesini, M.P. Anania, D. Angal-Kalinin, P. Antici, A Bacci, R. Bedogni, M. Bellaveglia, C. Biscari, N. Bliss, R. Boni, M. Boscolo, F. Broggi, P. Cardarelli, K. Cassou, M. Castellano, L. Catani, I. Chaikovska, E. Chiadroni, R. Chiche, A. Cianchi, J. Clarke, A. Clozza, M. Coppola, A. Courjaud, C. Curatolo, O. Dadoun, N. Delerue, C. De Martinis, G. Di Domenico, E. Di Pasquale, G. Di Pirro, A. Drago, F. Druon, K. Dupraz, F. Egal, A. Esposito, F. Falcoz, B. Fell, M. Ferrario, L. Ficcadenti, P. Fichot, A. Gallo, M. Gambaccini, G. Gatti, P. Georges, A. Ghigo, A. Goulden, G. Graziani, D. Guibout, O. Guilbaud, M. Hanna, J. Herbert, T. Hovsepian, E. Iarocci, P. Iorio, S. Jamison, S. Kazamias, F. Labaye, L Lancia, F. Marcellini, A. Martens, C. Maroli, B. Martlew, M. Marziani, G. Mazzitelli, P. Mcintosh, M. Migliorati, A. Mostacci, A. Mueller, V. Nardone, E. Pace, D.T. Palmer, L. Palumbo, A. Pelorosso, F. X. Perin, G. Passaleva, L. Pellegrino, V. Petrillo, M. Pittman, G. Riboulet, R. Ricci, C. Ronsivalle, D. Ros, A. Rossi, L. Serafini, M. Serio, F. Sgamma, R. Smith, S. Smith, V. Soskov, B. Spataro, M. Statera, A. Stecchi, A. Stella, A. Stocchi, S. Tocci, P. Tomassini, S. Tomassini, A. Tricomi, C. Vaccarezza, A. Variola, M. Veltri, S. Vescovi, F. Villa, F. Wang, E. Yildiz, F. Zomer, Technical Design Report EuroGammaS proposal for the ELI-NP Gamma Beam System, arXiv:1407.3669.

[30] D. Alesini, R. Boni, B. Spataro, C. Vaccarezza, L. Ficcadenti, V. Pettinacci, M. Migliorati, A. Mostacci, L. Palumbo, L. Serafini, The damped C-band RF structures for the European ELI-NP proposal, in: Proceedings of the 4th International Particle Accelerator Conference (IPAC 2013), Shanghai, China, May, 2013, pp. 2726-2728.

[31] D. Alesini, S. Bini, R. Di Raddo, V. Lollo, L. Pellegrino, L. Ficcadenti, V. Pettinacci, L. Palumbo, L. Serafini, Design and RF test of damped C-band accelerating structures for the ELI-NP linac, in: Proceedings of the 5th International Particle Accelerator Conference (IPAC 2014), Dresden, Germany, June 2014, pp. 3856 3859.

[32] D. Alesini, R. Boni, G.D. Pirro, R.D. Raddo, M. Ferrario, A. Gallo, V. Lollo, F. Marcellini, L. Palumbo, V. Spizzo, A. Mostacci, G. Campogiani, S. Persichelli, A. Enomoto, T. Higo, K. Kakihara, T. Kamitani, S. Matsumoto, T. Sugimura, K. Yokoyama, S. Verdu-Andres, The C-band accelerating structures for SPARC photoinjector energy upgrade, J. Instrum. 8 (05) (2013) P05004, http://dx.doi. org/10.1088/1748-0221/8/05/P05004.

[33] M. Ferrario, D. Alesini, M.P. Anania, A. Bacci, M. Bellaveglia, O. Bogdanov, R. Boni, M. Castellano, E. Chiadroni, A. Cianchi, S. Dabagov, C.D. Martinis, D. D. Giovenale, G.D. Pirro, U. Dosselli, A. Drago, A. Esposito, R. Faccini, A. Gallo, M. Gambaccini, C. Gatti, G. Gatti, A. Ghigo, D. Giulietti, A. Ligidov, P. Londrillo S. Lupi, A. Mostacci, E. Pace, L. Palumbo, V. Petrillo, R. Pompili, A. Rossi, L. Serafini, B. Spataro, P. Tomassini, G. Turchetti, C. Vaccarezza, F. Villa, G. Dattoli, E.D. Palma, L. Giannessi, A. Petralia, C. Ronsivalle, I. Spassovsky, V. Surrenti, L. Gizzi, L. Labate, T. Levato, J. Rau, SPARCLAB present and future, Nucl. Instrum. Methods Phys. Res. B 309 (2013) 183-188, http://dx.doi.org/ 10.1016/j.nimb.2013.03.049.

[34] T. Sugimura, T. Kamitani, K. Yokoyama, K. Kakihara, M. Ikeda, S. Oshawa, SKIP a pulse compressor for SuperKEKB, in: Proceedings of the 22nd International Linear Accelerator Conference (LINAC04), Lubeck, Germany, August, 2004, pp. 754-756.

[35] COMEB website. (last accessed 20/07/2016).〈www.comeb.it〉.

[36] TIARA project website. (last accessed 20/07/2016). 〈www.eu-tiara.eu/rtd/in dex.php?id $=44\rangle$.

[37] C. Nantista, S. Tantawi, V. Dolgashev, Low-field accelerator structure couplers and design techniques, Phys. Rev. Spec. Top. Accel. Beams 7 (2004) 072001, http://dx.doi.org/10.1103/PhysRevSTAB.7.072001.

[38] D. Alesini, A. Citterio, G. Campogiani, L. Ficcadenti, M. Migliorati, A. Mostacci, L. Palumbo, S. Persichelli, R. Zennaro, Tuning procedure for traveling wave structures and its application to the C-band cavities for SPARC photo injector energy upgrade, J. Instrum. 8 (10) (2013) P10010, http://dx.doi.org/10.1088/ $1748-0221 / 8 / 10 /$ P10010. 